\title{
ANALISIS KETIDAKLANGSUNGAN EKSPRESI ANTOLOGI PUISI $D O A$ UNTUK ANAK CUCU KARYA WILLYBRORDUS SURENDRA BHAWANA RENDRA BROTOATMOJO
}

\author{
Thoyib \\ MTs Manbaul Ihsan \\ Mojopurogede Bungah Gresik
}

\begin{abstract}
The purpose of research include five things: the expression indirect include; Second, Reading of heuristics and reading hermeneutic, third, matrices, models and variants, fourth,hipogram (hypogram).in ontology poetry Doa untukAnakCucu by Willybrordus Surendra Bhawana Rendra Brotoatmojo. The research approach used is semiotic, that is studying the indirect expression to poetry by way of linguistic influence the meaning of a literary work as a whole and the effects on the reader. Data collection techniques using literature techniques, see and record.The data analysis technique that analyzes three grooves flowing with concurrent activities. That is; data reduction, data presentation, drawing contents in poetry. Methods of data analysis used in this study is a semiotic method, and approach indirect expression.The conclusions of this research consists of four things. First, the expression indirect include; Second, Reading of heuristics and reading hermeneutic, third, matrices, models and variants, fourth, hipogram (hypogram).
\end{abstract}

Keywords: the indirect expression, semiotic

Abstraksi:Tujuan penelitian meliputi lima hal yaitu (1) ketidaklangsungan ekspresi (2) pembacaan heuristik. (3) pembacaan hermenuetik (4) materik, model dan varian (5) hipogram (hypogram) dalam ontologi puisi Doa untuk Anak Cucu karya Willybrordus Surendra Bhawana Rendra Brotoatmojo.Teknik pengumpulan data menggunakan teknik pustaka, simak dan catat. Teknik analisis data yaitu analisis mengalir dengan tiga alur kegiatan bersamaan.Yaitu; reduksi data, penyajian data, penarikanisi dalam puisi. Metode analisis data yang digunakan dalampenelitian ini adalah metode semioti. Hasil penelitian ini adalahPertama,ketidaklangsungan ekspresi meliputi; (1) penggantian arti (displacing of meaining) dengan gaya bahasa metafora dan personifiksi (2) penyimpangan arti (distorting of meaining) terdiri dari: ambiguitas, kontradiksi, nonsesnse (3) penciptaan arti (creating of meaning) yaitu; sajak/rima, homologues, kedua pembacaan heuristic dan pembacaan hermenuetik, ketiga, matriks, model dan varian, keempat, hipogram (hypogram)

Kata kunci:ketidaklangsungan ekspresi, semiotik 


\section{PENDAHULUAN}

Puisi merupakan salah satu genre sastra yang makin lama makin berkembang dari waktu ke waktu, baik dari segi bentuk maupun jumlah peminatnya. Sebagai sebuah karya sastra, puisi tentunya memiliki hakikat dan fungsi yang disebut dulce et utile. Dulce artinya menyenangkan, sedangkan utile artinya bermanfaat. Jika menyoroti hakikat dulce, penyair berusaha sebisa mungkin menggunakan berbagai cara untuk membuat puisinya memiliki kesan yang menyenangkan.Bahasa puisi berbeda dengan bahasa sehari-hari. Bahasa puisi mengekspresikan sesuatu secara khas. Bahasa puisi singkat, padat dan kaya makna. Selain itu, menurut Siswantoro (2005: 3) "bahasa puisi bersifat plastis, namun mampu mengakomodasi berbagai dimensi makna di balik apa yang tersurat". Puisi penuh makna.

Puisi harus dipahami sebagai sebuah satuan yang bersifat struktural atau bangunan yang tersusun dari berbagai unsur kebahasaan. Oleh karena itu, pembacaan hermeneutik pun dilakukan secara struktural atau bangunan yang tersusun dari berbagai unsur kebahasaan. Artinya, pembacaan itu bergerak secara bolak-balik dari suatu bagian ke keseluruhan dan kembali ke bagian yang lain dan seterusnya. Pembacaan ini dilakukan pada interpretasi hipogram potensial, hipogram aktual, model, dan matriks (Riffaterre,1978:5).

$$
\begin{aligned}
& \text { Menurut Riffaterre (dalam } \\
& \text { Pradopo, }
\end{aligned}
$$

2009: 210) ketidaklangsungan pernyataan puisi itu disebabkan oleh tiga hal, yaitu: penggantian arti (displacing of meaning), penyimpangan arti (distorting of meaning), dan penciptaan arti (creating of meaning). Pada umunya kata-kata kiasan mengganti sesuatu yang lain, lebih-lebih metafora dan metomini Riffaterre (dalam Pradopo, 2009: 212). Dalam penggantian arti ini suatu kata (kiasan) berarti yang lain (tidak menurut arti yang sesungguhnya). Menurut Riffaterre (dalam Pradopo, 2009: 213) penyimpangan
Humanis Vol. 12 No. 1

terjadi bila dalam sajak ada ambiguitas, kontradiksi, ataupun nonsense.

Hal ini seperti yang dikemukakan oleh Julia Kristeva (tokoh semiotic terkenal) (Preminger dkk) dalam Pradopo, 2009: 212). Mengemukakan bahwa ambiguitas seperti itu puisi memberi kesempatan kepada pembaca untuk memberikan arti sesuai dengan asosiasinya.

Menurut Riffaterre(dalam Rina:2016:7) Matriks, Model, dan Varian dalam Puisi. Secara teoritis puisi merupakan perkembangan dari matriks menjadi model dan ditransformasikan menjadi varianvarian.

Menurut Riffaterre (dalam Pradopo:2009:220) bilang ruang teks (spasi teks) berlaku sebagai prinsip pengorganisasian untuk membuat tandatanda keluar dari hal ketatabahasaan yang sesungguhnya secara linguistik tidak ada artinya, misalnya simitri, rima, enjambement, atau ekuivalensiekuivalensi makna (semantik) diantara persamaan-persamaan posisi. Preminger (dalam Rina:2016:7) konvensi sastra sebagai konvensi tambahan. Arti bahasa adalah arti(meaning), sedangkan arti sastra adalah "arti dari arti"(meaning of meaning).Intisari dari serangkaian teks, disebut matriks, aktualisasi pertama matriks adalah model yang dapat berupa kata atau kalimat tertemtu. Matriks senantiasa terwujud dalam bentuk-bentuk varian yang ditentukan oleh model.

Ketidaklangsungan menurut Michael Riffaterreadalah penggantian arti, penyimpangan arti, dan penciptaan arti dalam teks puisi.Ekspresi adalah pengungkapan atau proses menyatakat (yaitu memperlihatkan atau menyatakan maksud, gagasan, perasaan, dan sebagainya)

Penggantian arti (displancing of meaining) adalah penggunan bahasa kiasan yang melihat sesuatu dengan perantaran benda baik sebagai pengganti nama benda tersebut ke dalam bahasa puisi. Penyimpangan arti (distorting of meaning) adalah pemencongan arti dari bahasa yang ditulis akibat mempunyai makna ganda, dan penggunaan bahasa yang menyatakan sesuatu secara 
kebalikannya serta kata-kata yang secara lingguitik tidak mempunyai arti, tetapi mempeunyai makna karena konvensi puisi.Penciptaan arti (creating of meaning) adalah pengorganisasian ruang teks yang menimbulkan makna intensitas dalam puisi,walaupun secara linguistik tidak ada artinya.

Pembacaan heuristik adalah pembacaan itu didasarkan pada sistem dan konvensi bahasa, atau interpretasi tahap pertama. Pembacaan hermeneutik adalah teori interpretasi terhadap karya sastra, atau pembacaan yang didasarkan pada konvensi sastra.

Matriks adalah konsep abstrak yang tidak pernak teraktualisasi dan tidak muncul dalam teks. Model adalah teks puisi secara keseluruhan, atau sifat puitisnya.Varian-varin adalah bentuk transformasi dari model Hipogram (hypogram) adalah teks yang menjadi latar penciptaan sebuah teks baru (sajak) atau landasan bagi penciptaan karya yang baru Berdasarkan paparan diatas, perlu adannya penelitian bertujuan (1) Mendeskripsikan bagian puisi yang mengandung Ketidaklangsungan Ekspresi meliputi: penggantian arti (displacingof meaining), penyimpangan arti (distortingof meaining), penciptaan arti (creating of meaning) Mendeskripsikan pembacaan heuristic dan pembacaan (3) Mendeskripsikan bagian puisi yang mengandung matriks, model dan varian-varian.(4) Mendeskripsikan bagian puisi yang mengandung hipogram (hypogram) dalam antologi puisi Doa untuk Anak Cucu karyaWillybrordus Surendra Bhawana Rendra Brotoatmojo(Prespektif Semiotik Michael Riffaterre).

\section{METODE}

\section{PENELITIAN}

Penelitian ini dirancang dalam bentuk penelitian kualitatif yang disesuaikan dengan keperluan penelitian semiotik.
Teknik pengumpulan data yang tepat adalah teknik baca, simak, catat. Teknik ini dikemukakan oleh Ratna (2010:245-246). Membaca dalam pengumpulan data teks novel dilakukan dengan cara memberikan perhatian yang benar-benar terfokus pada obyek. Proses membaca dengan memberikan perhatian penuh terhadap obyek. Proses membaca dengan memberikan perhatian penuh terhadap obyek tersebut sebagai proses menyimak kemudian diikuti dengan kegiatan mencatat data. Karena proses pemerolehan data melalui teknik membaca, menyimak, dan mencatat, maka teknik ini disebut teknik baca, simak, catat.

\section{HASIL PENELITIAN}

Pada bagian ini di paparkan hasil peneliti melakukan tahap ini untu mengelompokkan data dari proses pembacaan keseluruhan antologi puisi Doa untuk Anak Cucu Karya W.S. Rendra untuk menggambarkan (1) Ketidaklangsungan ekspresi semiotik (2)Pembacaan heuristik dan pembacaan hermenuetik semiotik (3) Matriks, model dan Varian dan (4) Hipogram (hypogram)Michael Riffaterre.

\section{Ketidaklangsungan ekspresi}

Dalam antologi puisi Doa untuk Anak Cucu karya W.S. Rendra ditemukan ketidak langsungan ekspresi meliputi penggantian arti terdapat gaya bahasa metafora, personifikasi, sinekdoki, dan metonimi. Penyimpangan arti disebabkan oleh ambiguitas, kontadiksi, dan nonsesnse. Penciptaan arti disebabkan oleh pengorganisasian enjambement, sajak, dan homologue

Supaya bersih jiwa hamba.(DuAC, 2010:5) Aku merindukan mata bayi (DuAC, 2010:7) Melepas sepatu yang penuh kisah (DuAC, 2010:10)

Karena Allah yang mempunyai sifat pengampun, tidak salah dosa-dosa 
manusia (hamba) harus dibersikan agar menjadi "Bersih Jiwa" . menggantikan arti suatu keadaan bahagia, tenang, taat, seperti "(QS. Asy Syams: 9-

10)artinya "Sungguh berbahagia orang yang menyucikan jiwanya dan sungguh merugi orang yang justru mengotorinya."

Metaforis menyatakan bahwa "mata bayi" (menggantikan suatu pandangan yang kemurnian, yang suci, jernih, tidak kotor), Metaforis menyatakan bahwa "sepatu yang penuh kisah" ini (menggantikan suatu benda, alas kaki, pembungkus kaki, untuk perjalanan dinas, untuk bekerja, setelah berhari-hari dan berbulanbulan dipakai, akhirnya dilepas, setelah banyak nostalgia dengan pembungkus kakitersebut)

Dan nafas-Mu membimbing kelakuanku. (DuAC,

2010:5)

Dan mandi mengusir rasa gerah(DuAC, 2010:8) Di antara tiga gunung

Memeluk rembulan. (DuAC,

2010:10) Sungai mengandung pengkhianatan $(D u A C$,

2010:20)

Ratap tangis menerpa pintu kalbuku. (DuAC,

2010:25)

Bumi meratap dan terluka. (DuAC, 2010:28) Musik menyundul-nyundul atap (DuAC, 2010:30) mendengar hujan menghajar dinding $(D u A C$,

2010:33)

gedung-gedung tinggi,

membelah jalan raya, (DuAC, 2010:34)

Jiwaku menyanyikan tembang maskumambang. (DuAC, 2010:40)

Udara yang rama menyapa tubuhku. (DuAC,

2010:45)

Baris sajak-sajak diatas mengandung gaya bahasa personifikasi mengisyaratkan, benda-
Humanis Vol. 12 No. 1

banda yang digambarkan mempunyai sifat seperti manusia atau hidup.

\section{Pembacaan heuristik dan pembacaan hermenuetik \\ Pembacaan hermenuetik, dengan}

sistem deskriptif sebagai hipogram potensialnya, dijumpai pasangan oposisional, yaitu berlaksa hasta. Hasta' dalam konteks ini berimpilikasi pada keberadaan alam raya yang ditransformssikan ke dalam kata-kata; angin dan langit, gelap dan terang, arah dan kiblat, ruang dan waktu, dalam konteks ini berimplikasi pada kebesaran dan keberadaan fenomena alam yang ditransformasikan kedalam kata-kata: rasa duka dan kira, Musafir-musafir mengembara. manusia tak ada yang juara,Agama adalah kemah para pegembara, Mengema beragam doa dan puja.

\section{Matriks, model dan Varian}

Model 'Arti yang sama dalam bahasa-bahasa berbeda'di ekspansi ke dalam wujud varian-varian yang menyebar keseluruh sajak yaitu (1) adalah bayangan rahasia kehadiran-Mu, ya Allah. (2) Umat manusia tak ada yang juara, (3) Agama adalah kemah para pegembara, dan (4) Arti yang sama dalam bahasa-bahasa berbeda.

Setelah diketahui model dan varian- varian nya, diketahui pula matriks sajak ' Gumamku, ya Allah', yaitu seseorang telah kedatangan bayangan kerinduan. Seseungguhnya kerinduan itu merupakan akibat dari ketidaktahuan umat manusia yang belum menemukan agama sebagai tempat berlabu, tempat untuk berdoa, tempat unutuk memuja walaupun dengan bahasa yang berbeda, namun, tujuan dan maksud yang sama.

\section{Hipogram (hypogram).}

Judul Sajak ' Doa' yang mengungkapkan ketaatan dan pengampunan dalam rangka penyucian jiwa agar mampu melihat kebenaran, mendengarkan risalah, dan muda menerima bimbingan-Mu, ternyata 
berhipogram pada ayat suci Al-Quran tepatnya surah Asy -Syams ayat 9

\section{PEMBAHASAN}

Hasil Penelitian menujukan bahwa Antologi Puisi Doa untuk Anak Cucu karya Willybrordus Surendra Bhawana Rendra Brotoatmojo( prespektif semiotik Michael Riffaterre). Telah mengandungkeempat hal yaitu (1) Ketidaklangsungan ekspresi (2)Pembacaan heuristik dan pembacaan hermenuetik semiotik (3) Matriks, model dan Varian dan (4) Hipogram (hypogram).

\section{Ketidaklangsungan ekspresi}

Sajak Doa

Allah menatap hati.

Manusia menatap

raga.

Hamba bersujud kepada-mu, ya

Allah! Karena hidupku, karena matiku.

Bait pertama baris pertama secara metaforis menyatakan bahwa menatap hati (menggantikan suatu benda; berada di dalam tubuh manusia, terbuat dari segumpal darah-- berdasarkan Al Qur'an Surat Az-zumar ayat 22-23 Artinya “ Sesungguhnya di dalam diri manusia ada segumpal darah (hati) ..."--, berbentuk-secara umum seperti daun waru-dan mempunyai sifat-sifat cenderung dua; baik dan buruk, setelah bercampur dengan unsur-unsur tubuh). Yang mampu melihat hanya Allah, benda (hati) tersebut, kemana kecenderungannya baik atau buruk benda (hati) itu. Menatap raga (mengantikan suatu benda; yang terlihat secara fisik, dari ujung rambut sampai keujung kaki, membentuk manusia utuh, dan mempunyai nyawa agar berfungsi) benda atau bentuk tubuh ini bisa dilihat oleh manusia, perbuatan yang terlihat itu, perbuatan yang baik atau buruk. Setelah benda berupa hati dan berupa raga bersatu. "Hamba bersujud Kepada-Mu", Hati dan raga menjadi (hamba) melakukan sujud kepada Allah, yang mampu menatap segala-galanya. “
Karena hidupku, karena matiku", hidup dan mati itu hanya milik Allah. Seorang hamba hanya bisa melaksanakan sesuai dengan apa yang digariskan.

Allah yang maha benar.

Hamba mohon karunia dari

kebenaran yang telah paduka sebarkan.

Jauhkanlah hamba dari hal-hal buruk menurut paduka

dan dengan begitu akan buruk pula bagi hamba. Dekatkanlah hamba kepada halhal baik menurut paduka

dan dengan begitu akan baik pula bagi

hamba..(DuAC, 2010:5)

Bait kedua baris pertama Allah yang Maha Benar, "Maha Benar", Allah mempunyai sifat benar tidak pernah salah, Oleh karena itu," hamba mohon karunia dari kebenaran" sajak ini, menjelaskan semua berkah dari yang maha benar, dilanjutkan kalimat "yang telah padukan sebarkan", berarti Kebenaran itu telah tersebar keseluruh alam ini. Baris ketiga, sajak ini " hal-hal buruk", (menggantikan arti suatu benda yang tergolong buruk, seperti; iri hati, sombong, serakah, dan lain-lain) yang berakibat "buruk pula bagi hamba". Baris keempat sajak ini " Hal-hal baik" (menggantikan arti suatu benda yang tergolong baik, seperti; sifat sabar, cinta kasih, tidak sombong, suka menolong/membantu, taat dan lain- lain) yang berakibat " baik pula bagi hamba". Ya, Allah, ampunilah dosa-dosa hamba

Supaya bersih jiwa hamba.

Sehingga dengan begitu mata hamba

Bisa melihat cahaya-Mu.

Telinga hamba bisa mendengar bisikan-Mu. Dan nafas-Mu membimbing kelakuanku.(DuAC, 2010:5)

Bait ketiga baris, diatas karena Allah yang mempunyai sifat pengampun, tidak salah dosa-dosa manusia (hamba) harus dibersikan agar menjadi "Bersih Jiwa". menggantikan arti suatu keadaan bahagia, tenang, taat, seperti "(QS. Asy Syams: 910)artinya"Sungguh berbahagia orang yang menyucikan jiwanya dan sungguh merugi orang yang justru mengotorinya." , Baris 
kedua sajak ini, "mata", Mengantikan arti tidak hanya kedua mata saja, tetapi mata dengan arti yang luas, karena kalau hanya sepasang mata hanya bisa melihat yang tampak oleh mata. "bisa melihat cahayaMu". Mata yang mampu melihat cahaya kebenaran, yang datang dari Allah. Baris ketiga sajak ini "telinga" dan Mendengar bisikan-Mu" (menggantikan arti suatu bisikan yang tidak hanya suara semata, akan tetapi apa-apa yang baik menurut Allah, walau tidak hanya berupa suara saja, Misal; perbuatan, rasa, dan benda- benda lain. Baris keempat sajak ini "nafasMu", Menggantikan arti suatu benda yang mampu bergerak, tidak hanya sebuah suara saja, nafas yang mempu "membimbing kelakuan", Menggantikan arti suatu perbuatan dari jahat, buruk, menjadi perbuatan baik, benar dan nilai ibadah. Sehingan, semua yang terjadi bisa di kabulkan.

\section{Pembacaan heuristik dan pembacaan hermenuetik}

Sajak berjudul 'doa' tidak hanya berhubungan dengan kebutuhan meminta, tetapi dapat juga kehausan rohani dan jiwa manusia. Bait pertama, baris pertama dan kedua. "Allah menatap hati/Manusia menatap raga", dua baris sajak ini menandai terdapat perbedaan kemampuan, antara kemampuan Allah dan kemampuan manusia. Kemampuan Allah tak terbatas. Mampu melihat segala-galanya, namun kemampuan manusia terbatas hanya bisa menatap bagian luar atau fisik. Baris sajak,"Hamba bersujud kepada-Mu, ya Allah!", menujuk pada seorang menyembah atau menghambakan diri kepada yang mampu menatap hati, karena doa itu, terdapat dalam hati dan perintah. Sehinga , baris sajak ,"Karena hidupku, karena matiku",manusia dimuka bumi ini hidup dan mati harus diserahkan kepadanya.

Bait kedua mengambarkan yang mempunyai sifat maha benar hanya Allah. Sudah sewajarnya umat manusia kebenran dengan segala macam fakta di alam raya ini sudah tersebar. Tidak salah manusia hanya bisa memohon sesuai yang digariskan. Terdapat enjambement yang berfungsi menegaskan makna dan sebagai sarana mencapai pola persajakan. Ungkapan, "Jauhkanlah hamba dari hal-hal buruk menurut paduka/dan dengan begitu akan buruk pula bagi hamba.

Dekatkanlah hamba kepada hal-hal baik menurut paduka/dan dengan begitu akan baik pula bagi hamba", menandai bahwa yang bisa menjaukan hal-hal buruk hanya Allah. Begitu sebaliknya, yang bisa mendekatkan pada hal-hal baik hanya Allah. Kerena hal-hal buruk dan halhal baik semata-mata berasal atau bersumber dari Allah.

Bait ketiga mengandung ejambement,"Ya, Allah, ampunilah dosadosa hamba/Supaya bersih jiwa hamba", Enjambement ini berfungsi menciptakan hubungan yang saling menegaskan makna. Bentuk personifikasi untuk menambah nilai estestis. Dua baris sajak ini memiliki makna yang luas,'bersih jiwa'. Baris sajak," Sehingga dengan begitu mata hamba/Bisa melihat cahayaMu", menandai keinginan yang kuat untuk mendapatkan hidayah agar bias melaksanakan perintah Allah. Baris terakhir sajak, "Telinga hamba bisa mendengar bisikan-Mu/Dan nafas-Mu membimbing kelakuanku", menandai kecintaan kepada Allah mulai terdengar dari alunan-alunan bacaan kitab-kitab suci. Permintaan berupa contoh-contoh kelakuan yang sesuai dengan keinginan Allah.

$\begin{array}{r}\text { Secara } \\ \text { keseluruhan, pembacaan } \\ \text { yermenuetik }\end{array} \begin{aligned} & \text { disertai } \\ & \text { dapat }\end{aligned}$
ketidaklangsungan ekspresi,
dikemukakan bangunan kesatuan imajiner
sajak 'Doa' sebai berikut. Saja
'doa' merupakan gambaran bahwa
kemampuan manusia tidak sama dengan
kemampuan Allah. Kemampuan Allah
mampu menebus yang baru, menjadi niat,
sedangkan perbuatan belum terlaksana.
Oleh karena itu, seseorang perlu berdoa


memohon dijauhkan dari hal-hal buruk dan dekatkanlah hal-hal baik, karena kedua hal tersebut Allah telah memberikan izin. Fungsi mata, telinga dan perilaku itu semua kepunyaan Allah.

Makna sajak 'Doa' intinya adalah untuk menyandarkan diri dalam menghadapi hidup ini, hanya satu sandaran yaitu Allah SWT. Menyandarkan hidup selain Allah akan berbahaya, karena Allah mengetahui sikap dan rencana umat manusia.

\section{Matriks, model dan Varian}

Sajak doa ini adalah menggambarkan kelebihan Allah, dan kelemahan manusia. Hanya Allah pemilik kebenaran, manusia hanya bisa memintak bimbinganNya Model dalam sajak Doa adalah 'Dan nafas-Mu membimbing kelakuanku'. Baris sajak ini, selain puitis juga karena segala bentuk peristiwa ritual yang terjadi bersumber dari umat manusia atas permohinan bimbingan yang diwujudkan dalam doa. Bentuk model nafas-Mu membimbing kelakuanku', ekuivalen dengan baris sajak yang terdapat dalam sajak Doa berikut ini.

Hamba bersujud kepada-mu, ya Allah! Karena hidupku, karena matiku. Allah yang maha benar. Hamba mohon karunia dari kebenaran yang telah paduka sebarkan. Jauhkanlah hamba dari hal-hal buruk menurut paduka dan dengan begitu akan buruk pula bagi hamba. Dekatkanlah hamba kepada hal-hal baik menurut Paduka dan dengan begitu akan baik pula bagi hamba. Ya, Allah, ampunilah dosadosa hamba Supaya bersih jiwa hamba.

Sehingga dengan begitu mata hamba Bisa melihat cahaya-Mu. Telinga hamba bisa mendengar bisikan-Mu. Dan nafas-Mu membimbing kelakuanku.(DuAc,2010:7)

$$
\text { Baris-baris sajak diatas }
$$
melukiskan berbagai peristiwa yang terjadi karena kelemahan manusia sehingga pasra adalah satusatunya hakekat hidup. Pada awalnya, muncul sebuah pertanyaan; apa yang menyebabkan,kareena hidup dan karena matiku.. Kemudian, kebenaran itu datangnya dari Allah semata. Sehinga, hal-hal buruk menurut paduka dan akan buruk pula bagi hamba. Begitupula hal- hal baik menueurt paduka dengan begitu akan baik pula bagi hamba. Selanjutnya dilukiskan umat manusia atas permohonan bersih jiwa berharap bisa melihat cahaya-Mu. Begirtu juga telinga dapat mendengar bisikan serta nafas membimbing atas kelakuaku.

$$
\text { Model 'Dan nafas-Mu }
$$

membimbing kelakuanku.'di ekspansi ke dalam wujud varian-varian yang menyebar keseluruh sajak yaitu (1) karena hidupku, karena matiku (2) Mohon hamba karunia dari kebenaran yang telah paduka sebarkan dan (3Dan nafas-Mu membimbing kelakuanku Varian pertama, Karena hidupku,

karena matiku,' merupakan bentuk rasa kepasrahan diri yang mendalam yang dirasakan oleh seseorang. Sifat kepasrahan itu, dibuktikan dengan aktivitas sujud, karena, hanya Allah yang mengetahui hati. Varian ini divisualisasikan dalam baris-baris sajak berikut.

Allah menatap hati. Manusia menatap raga.

Hamba bersujud kepada-mu, ya Allah!

Karena hidupku, karena matiku. (DuAc,2010:7)

Varian yang pertama ini merupakan bentuk rasa kepasrahan diri yang mendalam yang dirasakan oleh seseorang. Sifat kepasrahan itu, dibuktikan dengan aktivitas sujud, karena, hanya Allah yang mengetahui

hati

Varian ketiga, Dan nafas-Mu membimbing kelakuanku, merupakan wujud dalam bimbingan Allah kepada hambanya, Tanpa bimbingan atas kelakuan umat manusia celakalah manusia ini. Bimbingan dari jiwa yang bersih, pandangan mata agar bisa melihat cahaya kebenaran dan telinga mampu mendengar bisikan yang baik-baik Di 
varian ini divisualisaikan dalam barisbaris sajak berikut.

Ya, Allah, ampunilah dosa-dosa hamba

Supaya bersih jiwa hamba.

Sehingga dengan begitu mata hamba

Bisa melihat cahaya-Mu.

Telinga hamba bisa mendengar bisikanMu.

Dan nafas-Mu

membimbing kelakuanku.(DuAc,2010:7)

Varian kedua , Mohon hamba

karunia dari kebenaran yang telah paduka sebarkan, merupakan permohonan kebenaran yang bisa dilakukan oleh seseorang, karena semua kebenaran yang dilakukan umat manusia berasal dariNya.

Meskipun, hal-hal yang baik dan halhal yang buruk. Kebaikan dan keburukan yang datang itu, sensor yang diberikan Allah kepada Hambanya'. Varian ini divisualisasikan dalam baris sajak berikut.'.

Allah yang maha benar.

Hamba mohon karunia dari

kebenaran yang telah paduka sebarkan.

Jauhkanlah hamba dari hal-hal buruk menurut paduka

dan dengan begitu akan buruk pula bagi hamba. Dekatkanlah hamba kepada halhal baik menurut paduka

dan dengan begitu akan baik pula bagi hamba. (DuAc,2010:7

Varian kedua ini merupakan gambaran kebenaran yang telah paduka sebarkan, permohonan itu kebenaran yang bisa dilakukan oleh seseorang, karena semua kebenaran yang dilakukan umat manusia berasal dariNya. Setelah diketahui model dan varian- varian nya, diketahui pula matriks sajak ' Doa', yaitu menggambarkan kelebihan Allah, dan kelemahan manusia. Hanya Allah pemilik kebenaran, manusia hanya bisa memintak bimbinganNyadiatas melukiskan berbagai peristiwa yang terjadi karena kelemahan manusia sehingga pasra adalah satusatunya hakekat hidup .
Berdasarkan disertai penafsiran matriks, model, pembacaan, yang dan peskripsian dan varian-varian, akhirnya dapat dikemukakan maslah pokoknya sebagai berikut. Karena hidupku, karena matiku,' merupakan bentuk rasa kepasrahan diri yang mendalam yang dirasakan oleh seseorang. Sifat kepasrahan itu, dibuktikan dengan aktivitas sujud, karena, hanya Allah yang mengetahui hati.gambaran kebenaran yang telah paduka sebarkan, permohonan itu kebenaran yang bisa dilakukan oleh seseorang, karena semua kebenaran yang dilakukan umat manusia berasal dariNya, Tanpa bimbingan atas kelakuan umat manusia celakalah manusia ini. Bimbingan dari jiwa yang bersih, andangan mata agar bisa melihat cahaya kebenaran dan telinga mampu mendengar bisikan yang baik-baik.

\section{Hipogram (hypogram)}

Sajak Doa tersebut melukiskan seorang manusia yang selalu memohon kepada Allah SWT. Si aku terus menghambakan diri agar bersih jiwa dengan melaksakan segala perintah dan menjaukan segala larangan. Sebagaimana pada bait pertama baris ketiga dan keempat," Hamba bersujud kepada-Mu, ya Allah!/ karena hidupku, karena matiku. Si aku menyadari setelah melaksanakan perintah dan meminta ampunan atas dosa-dosa. Oleh karena itu, mata hamba mampu melihat cahaya kebenaran, telinga mampu mendengar risalah, dan mampu mengikuti bimbingan dari-Mu, ya Allah. Seperti tampak pada bait berikut.

Ya, Allah, ampunilah dosa-dosa hamba Supaya bersih jiwa hamba. Sehingga dengan begitu mata hamba Bisa melihat cahaya-Mu.Telinga hamba bisa mendengar bisikan-Mu. Dan nafas-Mu membimbing kelakuanku. (DuAc,2010:7)

Kutipan di atas memiliki makana yang sama dengan surah Asy -Syams ayat :9-10 
دقا نم حلفز هك (9)و اخدقب نمد سد ها (01) Artinya; "Sungguh berbahagia orang yang menyucikan jiwanya dan sungguh merugi orang yang justru mengotorinya. (Q.S. Asy -Syams : 9-10)

Fungsi hipogram : membuktikan kesucian jiwa Setelah sajak Doa di sejajarkan dengan surah ke-Asy -Syams :9-10 tampak ada hubungan intertesktual di antara keduanya. Surah ke-Asy Syams: $9-10$ oleh penyair ditransformasikan ke dalam bait ketiga sajak 'Doa' dalam rangka

fungsi membuktikan kesucian jiwa. Surah ke-Asy -Syams :9-10, tentang 'orang yang menyucikan jiwanya' yang ditransformasikan ke dalam bait ketiga sajak 'Doa' itu, berfungsi untuk membuktikan bahwa kesucian jiwa.

"Sungguh berbahagia orang yang menyucikan jiwanya"

Surah ke-Asy -Syams : 9-10 tentang kesucisn jiwa diteransformasikan ke dalam bait ketiga saja "Doa" itu, berfungsi untuk mengingatkan manusia agar selalu menyusikan jiwanya. Ayat tersebut sengaja diambil oleh penyair dan ditransformasikan ke dalam sajak 'Doa' . Pengambilan unsur itu tujuannya memeperlihatkan perlunya manusia selalu menyucikan jiwanya. Melalui sajaknya, penyair berharap manusia hendak melakukan bersih jiwa agar bisa menerima risalah dan mudah mendapatkan bimbinga-Nya.

Ada persamaan antara sajak 'Doa' dengan Surah ke-91 Asy -Syams :9-10 yaitu pada kata bersih jiwa. Surah ke91Asy -Syams : 9-10 berbunyi "berbahagia orang yang menyucikan jiwanya”, Katamenyucikan jiwanya yanng terdapat Surah ke-91Asy Syams:9-10, sengaja diambil oleh penyair kemudian ditransformasikan ke dalam bait ketiga sajak 'Doa'.

Sajak 'Doa' merupakan hasil refleksi atau penghayatan seorang penyair terhadap makna yang terkandung dalam kitab sucinya. Hal ini juga menujukan adanya pengaruh antara kepercayaan (agama) yang dianut penyair dengan karya-karya yang diciptakannya. Kitab suci, yang dipelajari dan dihayati oleh seorang penyair itu, dapat menjadi pijakan dalam berkarya, seperti terlihat dalam sajak Doa'. Sajak ini berisi ' kepasrahan dan pengabdian menuju kebersihan jiwa ' yang diekspresikan secara implisit, tetapi tertata untuh sehingga tetap terasa nilai- nilai kepuitisannya.

Bait ketiga saja'Doa' yang hipogram pada Surah ke-91Asy -Syams: 9-10, berfungsi melukiskan sungguh bahagia orang-orang yang bersih jiwa dengan muda mata bisa melihat cahaya kebenaran, telinga mampu mendengarkan risalah, dan jiwa yang bersih mudah menerima bimbingan dari Allah. Akibatnya, gambaran di atas manusia sungguh bahagia.

\section{SIMPULAN}

Hasil penelitian menujukkan bahwaanalisis ketidaklangsungan ekspresi antologi puisi berjudul Doa untuk Anak Сиси karya Willybrordus Surendra Bhawana Rendra Brotoatmojosebagai berikut.

Ketidaklangsungan ekspresi bagian penggantian arti (displacing of meaining) gaya bahasa metafora terdapat pada sajak (sajak Gumamku, ya Allah, sajak Doa, Syair Mata Bayi, sajak Tentang Mata, sajak Inlilah Saatnya, sajak Hak Oposisi, sajak Kesaksian tentang MastodonMastodon, dan sajak Rakyat Adalah Sumber Ilmu). Sedangkan, gaya bahasa personifikasi dalam sajak (sajak Doa, sajak Inlilah Saatnya, sajak Kesaksian tentang Mastodon-Mastodon, Sajak Bulan Mei 1998 di Indonesia, sajak Kesaksian akhir Abad, sajak Sagu Ambon, sajak Perempuan yang Cemburu, sajak Perempuan yang tergusur, sajak Di mana kamu, De'Na?, dan sajak Maskumambang). Bagian sajak yang mengandung penyimpangan arti (distorting of meaining) meliputi: ambiguitas, (sajak Tuhan, sajak Aku cinta pada-MU, dan sajak Gumamku, ya 
Allah). Kontadiksi hanya terdapat dalam (sajak Tentang Mata ). Nonsesnse terdapat dalam (sajak Inlilah Saatnya). Bagian sajak,penciptaan arti (creating of meaning) meliputi: sajak/rima ontologi puisi Doa untuk Anak Cucu terdapat dalam (sajak Maskumambang). Homologues terdapat dalam (sajak Hak Oposisi, sajak Kesaksian tentang Mastodon-Mastodon, dan sajak Rakyat Adalah Sumber Ilmu). Rumusan masalah kedua, pembacaan hueristik dan pembacaan hermenuetik pada seluruh sajak antologi Doa untuk Anak Cucu. Ketiga, matrik, model dan varian-varian, dan kempat, hipogram (hypogram)yang terdapat pada antologi puisi Doa untuk Anak Cucu karya Willybrordus Surendra Bhawana Rendra Brotoatmojo.

\section{DAFTAR RUJUKAN}

Pradopo, Rachmat Djoko. 2002. PengkajianPuisi. Yogyakarta : Gadjah Mada University Press.

Rendra, W.S 2013. Doa Untuk Anak Cucu. Yogyakarta: Bentang Pustaka

Ratih, Rina 2016. Teori dan Aplikasi Semiotik Michael Riffaterre Yogyakarta: Pustaka Pelajar

Sutardi, 2011. Apresiasi Sastra teori, aplikasi dan pembelajarannya. Lamongan: Pustaka ilalang.

Siswantoro, 2010. Metode Penelitian Sastra. Yogyakarta: Pustaka Pelajar

Ratna, Nyoman Kutha, 2013. Teori, metode dan teknik Penelitian sastra. Yogyakarta: Pustaka Pelajar

Pradopo, Rochmat Djoko,2012. Beberapa teori sastra, metode kritik dan penerapannya. Yogyakarta; Pustaka pelajar

Rendra, W.S. 2013. Doa untuk Anak Cucu: Yogyakarta: Bentang Pustaka. 